\title{
Analysis and Design of PMBLDC Motor for Three Wheeler Electric Vehicle Application
}

\author{
V. Sandeep ${ }^{1, *}$, and Sharankumar Shastri ${ }^{2}$ \\ ${ }^{1}$ Department of Electrical Engineering, Central University of Karnataka, Gulbarga 585367, India \\ ${ }^{2}$ Department of Electrical Engineering, Central University of Karnataka, Gulbarga 585367, India
}

\begin{abstract}
This paper deals with analysis and design of permanent magnet brushless de machine (PMBLDCM), primarily aimed for three wheeler applications. The motor sizing accounts for the forces acting on the motor and the design variables such as number of stator and rotor slots, stator and rotor dimensioning, air-gap approximation, slot sizing, flux per pole and permanent magnet sizing has been explained using simplified equations. The designed motor rated at $1.5 \mathrm{~kW}, 3000$ $\mathrm{rpm}, 120 \mathrm{~V}$ radial flux surface mounted permanent magnet rotor, is then assessed using analytical tools for design such as ANSYS's RMXprt to verify the analytically obtained results. These results are then verified using the computer aided analysis tool, finite element analysis, using ANSYS Maxwell, to obtain the electromagnetic characteristics of the motor for further modification of design.
\end{abstract}

\section{Introduction}

OF late, due to issues like increasing global oil demand and automobile emissions due to various factors [1], there has never been a higher demand for research and development of environmentally safer technologies to prevent this global resource depletion. One of the fastest technologies to develop among these has been in the field of electric vehicles (EVs). It has shown prominent advancements in the past 10-15 years. EVs can prove to be a very viable alternative to petroleum powered automobiles due to their features like zero tailpipe emissions, higher power efficiencies and lower costs compared to their gasoline counterparts [2].

Past developments in EV technologies, can be generally classified into these three subsystems: Battery technology/ energy storage, electric motors and their drives. As a key element of the EV system, electric motors have to offer high efficiency, wide-speed range, high power density and maintenance-free operation [3].

Fig. 1 shows the different types of motors being developed / used for EV applications.

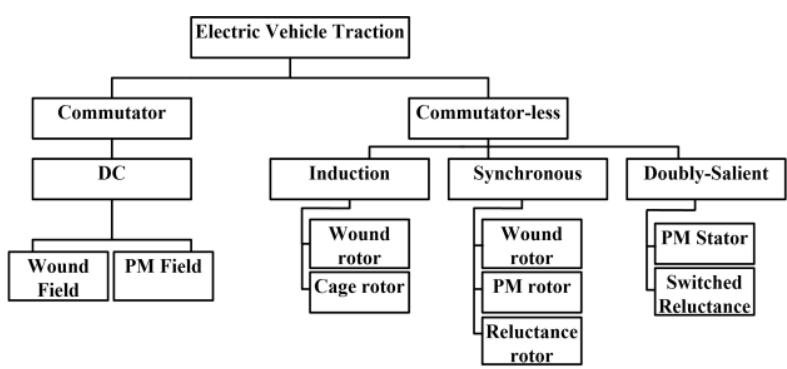

Fig. 1. Types of electric motors used for traction applications

Conventional motors like Induction machines are still widely accepted due to their low costs, high reliability and maintenance-free operation. However, conventional control methods cannot provide the required performance in EVs. With newer drive configurations rapidly developing due to advent of power electronics and control methods [4-12], conventional motors have also been able to provide desired performance, but lack efficiency in the lower speed ranges due to higher losses and have a limited constant power range. Permanent magnet (PM) motors, namely PM-synchronous motor and the Brushless-DC (BLDC) motors' use is becoming more prevalent in the EV market [13], due to their high power density, high efficiency, linear torque-speed nature, efficient thermal operation and availability of power electronics for efficient control, which make their use appropriate for traction applications. PM motors, as their name suggests, employ permanent magnets to generate the required operating torque. Despite recent increases in the price of permanent magnets, they have proved to still be profitable in operation costs. Many

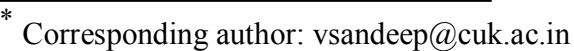


different types of design topologies for PM motors have been developed for various applications [14-18] to improve their efficiencies, optimize PM sizes and reduce unwanted cogging torque.

The paper aims to design a permanent magnet brushless dc motor for three-wheeler application, which has proved to be one of the more staple modes of transport in East-Asian countries, like India, Thailand, China, Vietnam and others. The design criteria and its principles are discussed including sizing and analytical design methods. Computer aided design and analysis is done using 2D FEM (ANSYS Maxwell) for electromagnetic modelling.

\section{Design Methodology}

Fig. 2 shows the overview of the design methodology for calculation of average power required for sizing of the electric motor for the $\mathrm{EV}$. Iterative loops are not mentioned here, but have been implemented in the procedure, where ever required.

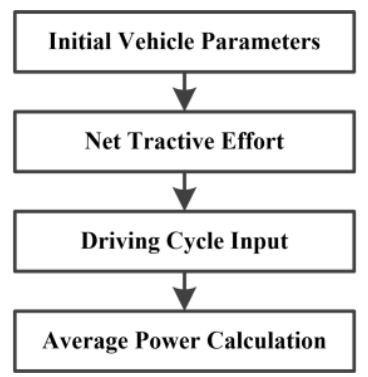

Fig. 2. Methodology followed to calculate the average power needed for the EV

Initial vehicle parameters include the mass of the vehicle under study. The parameters added are, mass of the vehicle $\left(M_{v}\right)$, the coefficients of drag and rolling resistance $\left(C_{d}, \mu_{r r}\right)$ etc. The vehicle taken for reference is a popular model of three-wheeler vehicle, the 'Bajaj RE-2S', shown in Fig. 3.

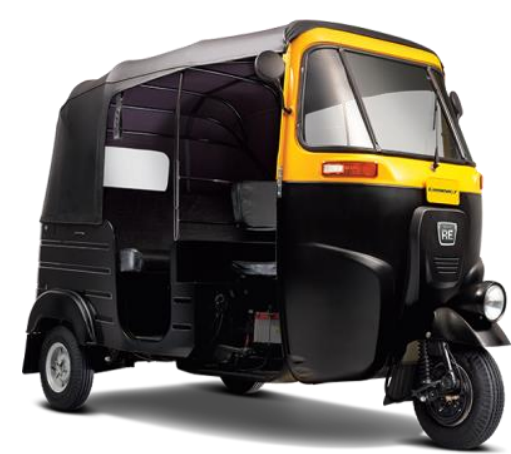

Fig. 3. Bajaj RE-2S three-wheeler as reference model

The parameters for the reference vehicle are presented in Table 1, showing the various metrics used for the force model [2].
Table 1. Values of different parameters of the reference model

\begin{tabular}{|l|l|l|}
\hline Sl.no & Component/Parameter & Values \\
\hline 1 & Vehicle dimensions & $\begin{array}{l}1300 \mathrm{~mm} \times 2625 \\
\mathrm{~mm} \times 1710 \mathrm{~mm}\end{array}$ \\
\hline 2 & Tires (Front-Rear, R) & $4.00-8,4 \mathrm{PR}$ \\
\hline 3 & Drag coefficient $\left(C_{d}\right)$ & 0.45 \\
\hline 4 & Rolling resistance $\left(\mu_{r r}\right)$ & 0.01 \\
\hline
\end{tabular}

These parameters are then input into a force model to calculate the net tractive effort needed to be generated to accelerate, and run the vehicle at required speeds.

The method to calculate the net tractive force on the vehicle is as follows:

a. The net tractive effort on any vehicle comprises of four main forces: Aerodynamic drag force $\left(F_{w}\right)$, rolling resistance force $\left(F_{r}\right)$, acceleration force $\left(F_{a}\right)$, and gradient force $\left(F_{g}\right)$.

b. Aerodynamic force $\left(F_{w}\right)$ is force is produced due to the friction of the vehicle moving through air. It is a function of the body shape and area of the vehicle.

$$
F_{w}=\frac{1}{2} \rho A_{f} C_{d}\left(V+V_{w}\right)^{2}
$$

c. Rolling resistance $\left(F_{r}\right)$ is mainly caused due to the hysteresis in the tire material. The asymmetric distribution of the ground reaction forces on the tires when the vehicle is moving, causes rolling resistance. Depends on the weight of the vehicle.

$$
F_{r}=\mu_{r r} M_{V} g
$$

d. Acceleration force $\left(F_{a}\right)$ is the force required to take the vehicle from one speed to another.

$$
F_{a}=M_{V} a
$$

e. Gradient force $\left(F_{g}\right)$ is the force required to drive the vehicle up a slope. It is caused by the weight component of the vehicle along the downward direction. This force, either adds or opposes the forward motion of the vehicle based on descent or ascent.

$$
F_{g}=M_{V} g \sin \alpha
$$

The net tractive force $\left(F_{T E}\right)$ is the sum of all these forces,

$$
F_{T E}=F_{W}+F_{r}+F_{a}+F_{g}
$$

All the above mentioned forces can be seen in the vehicle dynamic force model in Fig.4. 


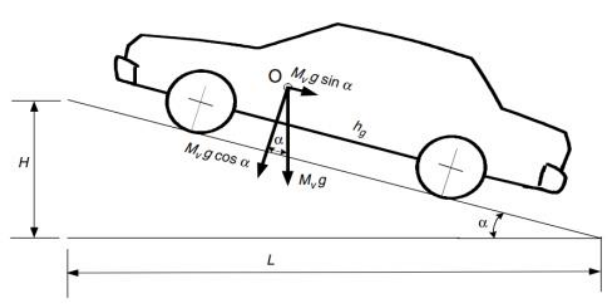

Fig. 4: Vehicle dynamics

Now that we have established all the performance variables, it is now necessary to evaluate the power needed for the vehicle under evaluation. The net force is calculated for a varying driving cycle input to simulate realistic driving behavior of the vehicle under different environments like urban or metropolitan cities. The driving cycle chosen for this study is the Modified Indian Driving Cycle (MIDC), developed by ARAI. This drive is to simulate realistic driving models for Indian roads. Fig. 5 shows the MIDC, as a function of varying velocity versus time.

\section{Modified Indian Driving Cycle}

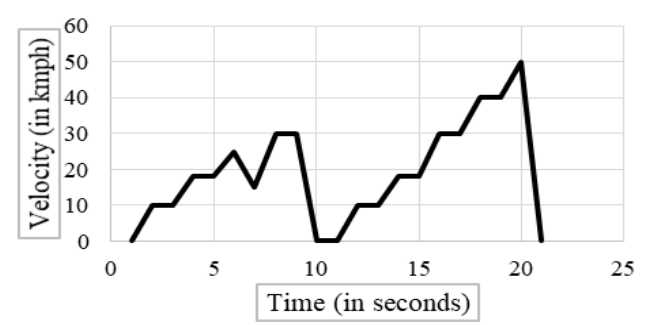

Fig. 5. Modified Indian Driving Cycle

Every point on the graph in Fig.4 has an initial velocity and a final velocity. For each of these points, the net tractive force is multiplied with the velocity difference to get the required power at that point.

The average power can be calculated and estimated as:

$$
P=F_{T E} \times V \text { watts }
$$

After calculating the power for each point on the drive cycle, its average value is the required power rating of the motor. The calculated average power rating of the motor, for the vehicle is about $1531 \mathrm{~W}$ or about $1.5 \mathrm{~kW}$.

\section{Motor Design}

The structure of the PMBLDC motor under design is shown in Fig. 6. It shows all the primary dimensions required for sizing and designing the motor. [19-21]

The PMBLDC motor type selected for design is a surface-permanent magnet type, meaning the permanent magnets are attached to the outer surface of the rotor.

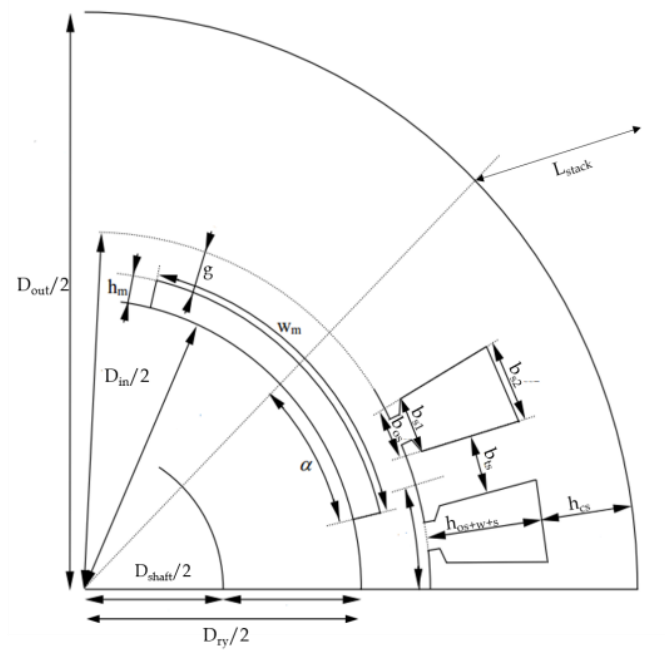

Fig. 6. Quarter motor cross section showing all the dimensions

Fig. 7 shows the procedure for the design of PMBLDC motor of rated power for the three-wheeler. Iterative loops are not mentioned here, but have been implemented in the procedure, where ever required. The followed methodology for design of the electric motor is as follows:

\subsection{Prediction of required power}

The required power for the motor has been determined using the net tractive effort. The estimated power rating required for the vehicle is about $1.5 \mathrm{~kW}$. 


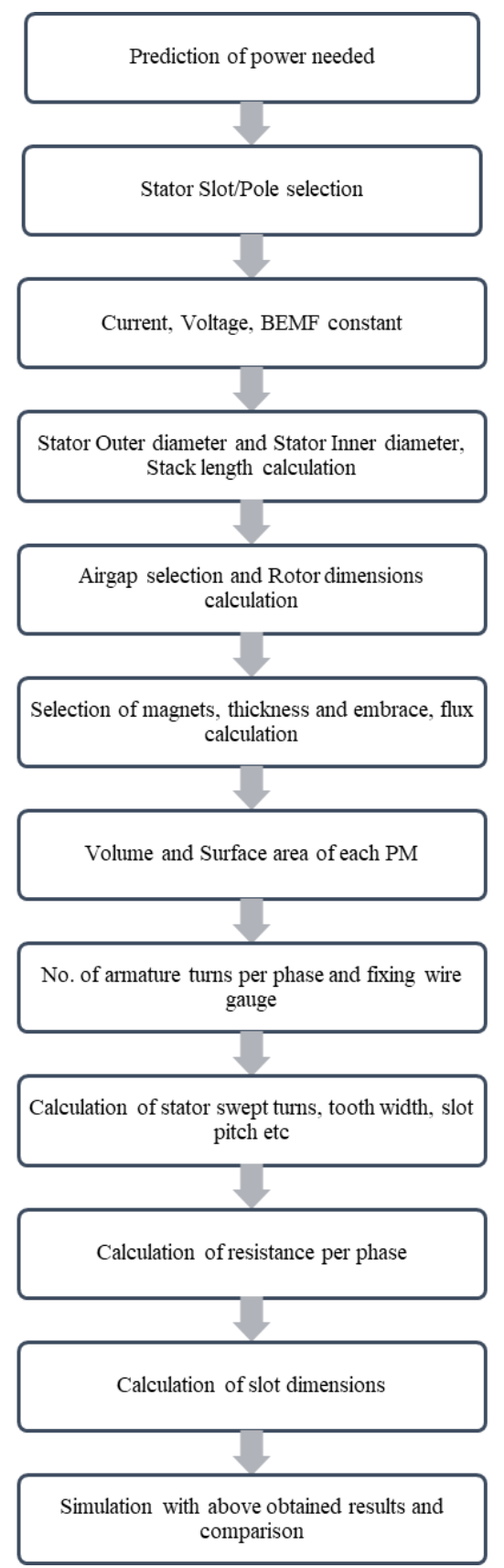

Fig. 7. Detailed procedure for design of the electric motor.

\subsection{Stator Slot/Pole Selection}

The number of slots on the stator is selected to be 24 $\left(\mathrm{N}_{\mathrm{s}}\right)$ and the number of rotor poles is selected to be 4 $\left(\mathrm{N}_{\mathrm{p}}\right)$. Proper slot/pole selection is very important to reduce effects like crawling and/or cogging.

\subsection{Ratings of the motor}

The motor to be designed has a power rating of $1.5 \mathrm{~kW}$, with an input voltage of $120 \mathrm{~V}$ DC. The required speed range is 3000 to $4000 \mathrm{rpm}$.

Motor power, $\mathrm{P}=2 \mathrm{EI}{ }_{a} \eta \cos \phi$

Now, armature current, $I_{a}=\frac{P}{2 E \eta \cos \phi}$
Substituting all the values, $I_{a}=6.57 \mathrm{~A}$

\subsection{Back EMF Constant $\left(\mathrm{K}_{\mathrm{E}}\right)$}

For a rated speed of $3000 \mathrm{rpm}$, and an input voltage of $120 \mathrm{~V}$, the back EMF constant, $K_{E}$ will be equal to $0.3437 \mathrm{~V}$-s/rad.

\subsection{Stator Outer and Inner Diameters ( $\left.D_{\text {in }} \& D_{\text {out }}\right)$}

The stator outer diameter is chosen to be $120 \mathrm{~mm}$ $\left(D_{\text {out }}\right)$ and the stator inner diameter is calculated to be 69 $\mathrm{mm}$.

\subsection{Stack length of the motor ( $\left.L_{\text {stack }}\right)$}

The following assumptions have been considered to calculate the stack length of the motor.

a. The airgap magnetic flux density is expected to be about $0.9 \mathrm{~T}$.

b. The stator line current density for a 4 pole motor should be approximately $A_{m}=30500 \mathrm{~A} / \mathrm{m}$.

c. The winding coefficient $k_{w}$ is 0.96

d. The no-load EMF to phase voltage ratio $\varepsilon$ is 0.83 .

The output coefficient $\left(\sigma_{\mathrm{p}}\right)$ now becomes,

$$
\sigma_{P}=\frac{P_{\text {out }} \cdot \varepsilon}{D_{\text {in }}^{2} \cdot L_{\text {stack }} \cdot n_{s}}=0.5 \pi^{2} k_{w} A_{m} B_{m g} \cos \phi
$$

Solving, we get $\sigma_{\mathrm{p}}=105334 \mathrm{VAs} / \mathrm{m}$, the length of the stack, $L_{\text {stack }}$ is equal to $50 \mathrm{~mm}$.

\subsection{Air gap (g) and rotor diameter $\left(D_{r}\right)$}

The air gap is kept at an optimum $0.5 \mathrm{~mm}$, and therefore the inner rotor diameter is equal to $68 \mathrm{~mm}$.

\subsection{Magnet thickness $\left(h_{m}\right)$ and rotor yoke diameter $\left(D_{\text {ry }}\right)$}

The thickness of the magnetic pole is chosen to be $2.5 \mathrm{~mm}$, and therefore the rotor yoke diameter $\left(\mathrm{D}_{\mathrm{ry}}\right)$ will be equal to $63 \mathrm{~mm}$.

\subsection{Surface area $\left(A_{\text {pole }}\right)$ and total volume of PM $\left(V_{m}\right)$}

With the above given dimensions, the area of each $\mathrm{PM}$ is $2474 \mathrm{~mm}^{2} /$ pole and the total volume of PMs is $24740 \mathrm{~mm}^{3}$.

\subsection{Armature turns per phase $\left(\mathrm{N}_{1}\right)$}

The number of armature turns per phase is equal to

$$
N_{1}=\frac{A_{m} p \tau}{m_{1} I_{a}}
$$

Substituting all values, the value of $N_{l}$ is equal to 118 turns.

\subsection{Computation of the flux per pole}

The flux in the air gap due to magnets,

$\phi_{p}=B_{m} \times 4 . A_{\text {pole }}$

The flux per pole is equal to

$\phi_{\text {magnet }}=B_{m} \times A_{\text {pole }}$

The flux per pole, $\phi_{\text {magnet }}$ is equal to $8.1642 \mathrm{e}-4$ webers for a $B_{m} 3.3 \mathrm{kG}$. 


\subsection{Slot sizing}

After establishing the no. of conductor turns/slot and the no. of parallel paths $(a)$, we can now calculate the dimensions of the slot, the useful slot area, $A_{s u}$, provided we adopt a slot fill factor, $K_{\text {fill }}$. Slot fill factor for round wire ranges from 0.35 to 0.65 . The slots designed are rounded trapezoidal in shape.

The useful slot area, $A_{s u}$ is given as,

$$
A_{s u}=\frac{\pi d_{c o}^{2} a \cdot n_{s}}{4 . K_{\text {fill }}}
$$

The key dimensions for the stator slot geometry are shown in fig. 8

Fig. 8: Stator slot dimensions

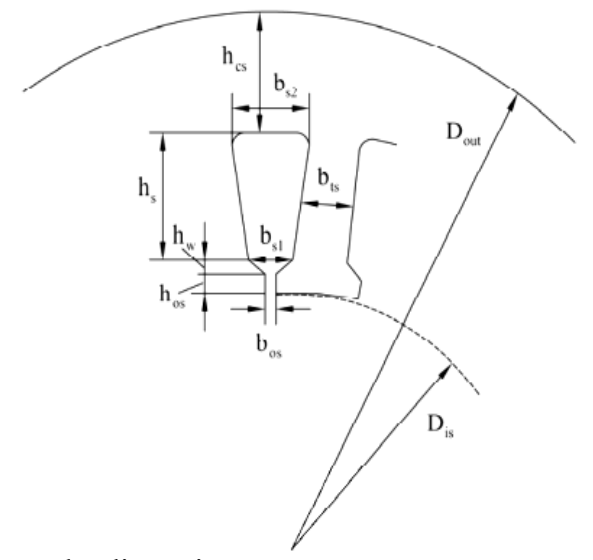

Table 2: Slot dimensions

\begin{tabular}{|c|c|c|}
\hline Sl.no & Dimension & Value (in mm) \\
\hline 1 & $b_{t s}$ & $5.25 \mathrm{~mm}$ \\
\hline 2 & $b_{o s}$ & $2 \mathrm{~mm}$ \\
\hline 3 & $h_{o s}$ & $1 \mathrm{~mm}$ \\
\hline 4 & $h_{w}$ & $2 \mathrm{~mm}$ \\
\hline 5 & $b_{s 1}$ & $4.57 \mathrm{~mm}$ \\
\hline 6 & $b_{s 2}$ & $4.67 \mathrm{~mm}$ \\
\hline 7 & $h_{s}$ & $11.77 \mathrm{~mm}$ \\
\hline 8 & $b_{c s}$ & $10.5 \mathrm{~mm}$ \\
\hline
\end{tabular}

\section{Analytical Results}

After obtaining the required dimensions, analytical results of values such as torque, power, phase current, resistance and back EMF are estimated to be as follows.

\begin{tabular}{|c|l|l|}
\multicolumn{3}{|c}{ Table 3: Analytical results } \\
\hline Sl.no & \multicolumn{1}{|c|}{ Dimension } & Estimated result \\
\hline 1 & Shaft torque & $4.77 \mathrm{Nm}$ \\
\hline 2 & Output power & $1500 \mathrm{~W}$ \\
\hline 3 & No load input current & $6.57 \mathrm{~A}$ \\
\hline 4 & Back EMF & $120 \mathrm{~V}$ \\
\hline 5 & Per phase resistance & $0.25 \mathrm{ohms}$ \\
\hline 6 & No load speed & $3400 \mathrm{rpm}$ \\
\hline 7 & No load air-gap flux density & $0.74998 \mathrm{~T}$ \\
\hline 8 & Cogging torque & $0.657 \mathrm{Nm}$ \\
\hline 9 & Full load input current & $13.49 \mathrm{~A}$ \\
\hline 10 & Full load efficiency & $92.59 \%$ \\
\hline 11 & Full load torque & $5.23 \mathrm{Nm}$ \\
\hline
\end{tabular}

Table. 3 shows that the performance of the motor is well within the required ratings. But since analytical methods of calculations, always offer various types of estimation to be considered beforehand to obtain the necessary results.

To get more accurate results, 2D finite element analysis is done on the motor. This offers a high precision method to calculate various parameters of the motor using the finite element method (FE).

\section{Final Element Analysis (2D)}

Finite element method is employed into this design using ANSYS's Maxwell package, which offers both 2D and 3D FE solution methods for any electromagnetic problem type. The motor can be designed in Maxwell's 2D environment or can be imported from ANSYS's RMxprt package.

After designing the motor in the $2 \mathrm{D}$ environment, the software meshes the model, to simplify the problem and obtain solutions. The fineness of the mesh is directly proportional to the number of nodes formed. More the nodes, therefore more accurate the output result.

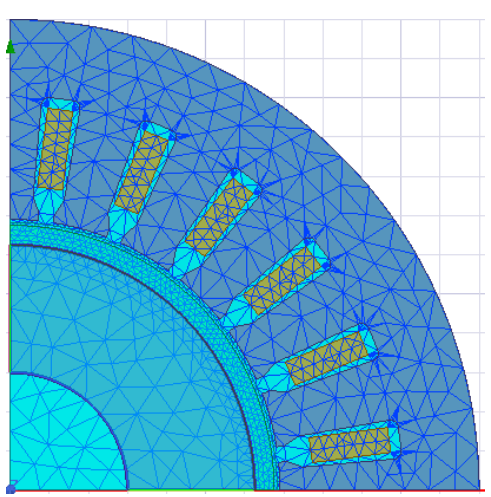

Fig. 9. Optimized mesh for 2D analysis

Fig. 9. shows the optimized mesh for a quarter-fraction model of the motor in ANSYS's Maxwell environment. After solving the 2D FE problem, the following results are obtained for the motor outputs.

\subsection{Torque output}

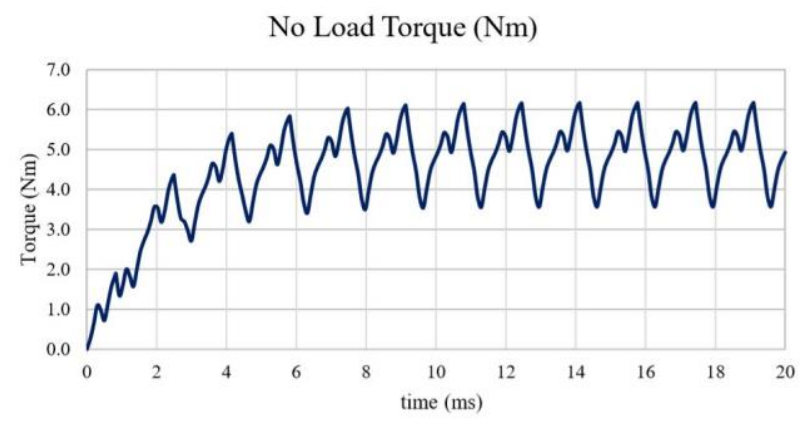

Fig. 10. Output torque

Fig. 10. shows the characteristic torque output for a BLDC motor, the rated torque is averaged at $5 \mathrm{Nm}$. There are also ripples in the characteristic curve due to high cogging torque in a BLDC motor. These can be reduced using methods to reduce cogging torque. 


\subsection{Output Speed}

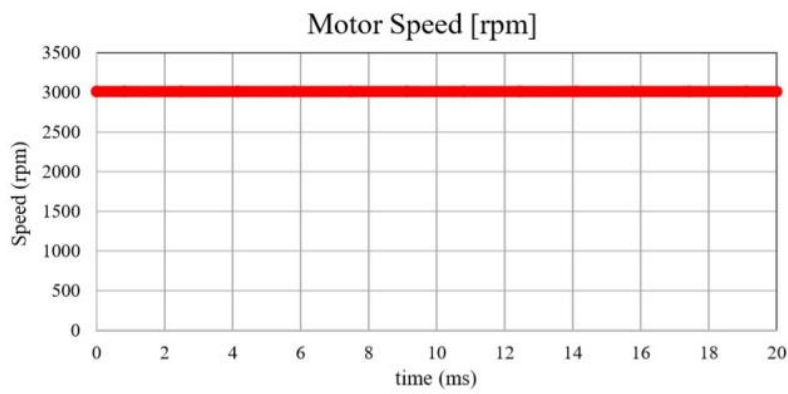

Fig. 11. Output speed

Fig. 11 shows the output speed for the motor, rated at the required speed of $3000 \mathrm{rpm}$.

\subsection{Winding Currents}

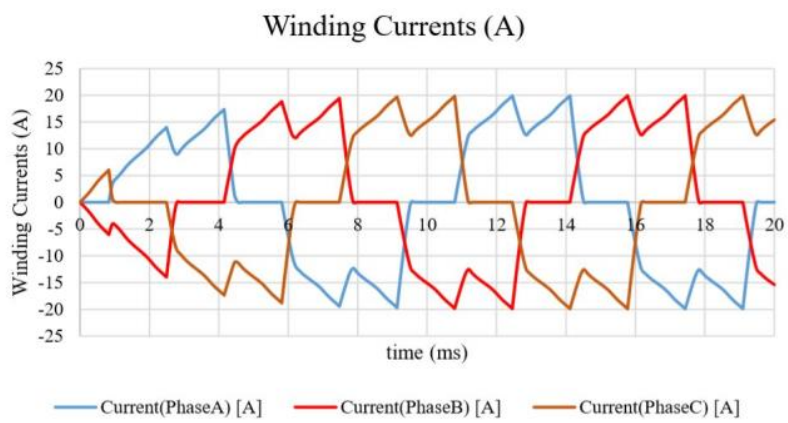

Fig. 12 Phase winding currents

Fig. 12 shows the phase winding currents in the motor. In addition to this, the FE method also can display accurate distributions of several fields, namely flux density, current density and their vectors. These can be utilized to understand the distribution of flux, saturation, temperature etc. and improve the model by optimizing to reduce the undesired effects.

Fig. 13, 14, and 15 show the plot distribution for flux density, current density, flux lines and current distribution plots.

Fig 13. shows the distribution of flux along the cross section of the motor. The maximum flux density along the cross section does not exceed $2 \mathrm{~T}$, which is still lesser than the saturation limits of the ferromagnetic material used. Current density plot $(\mathrm{A} / \mathrm{m})$ in Fig.14, and flux distribution in Fig. 15 are both within practical permissible limits.

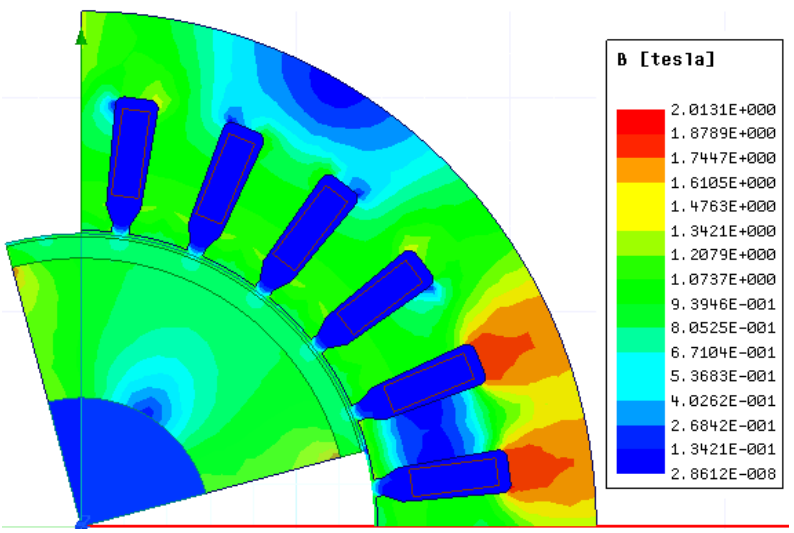

Fig. 13. Flux density plot

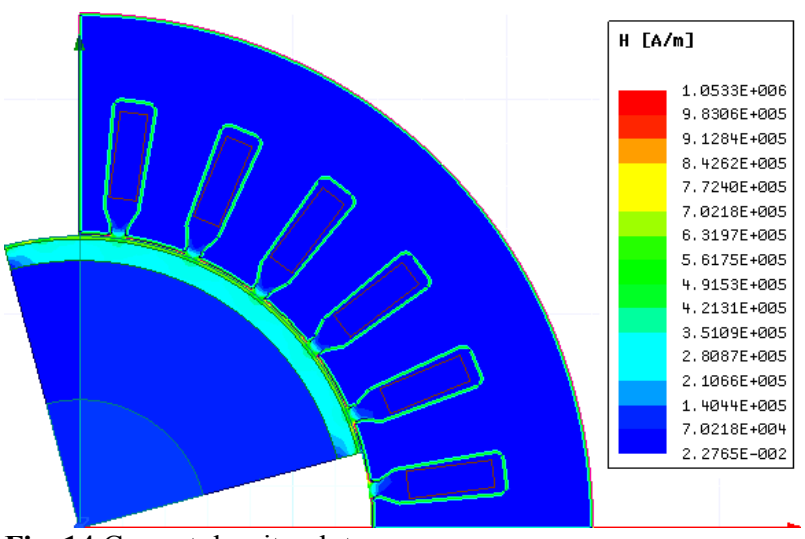

Fig. 14 Current density plot

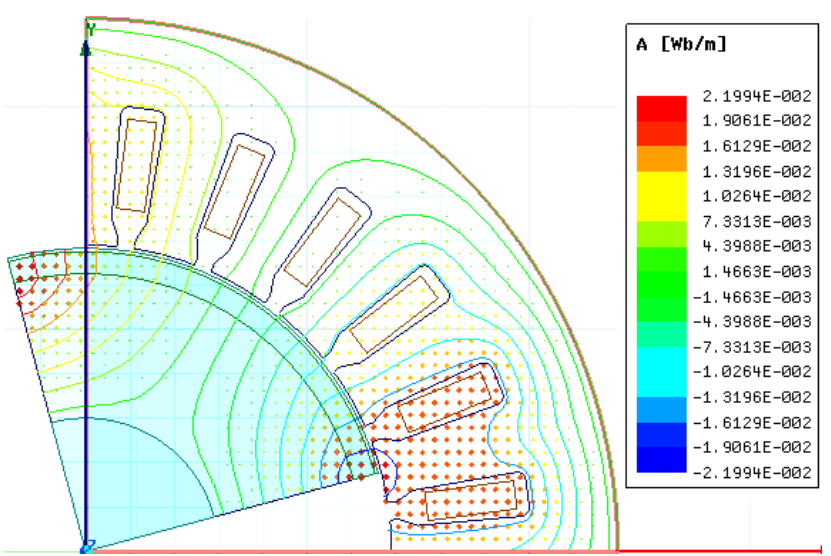

Fig. 15 Flux pattern and Current distribution plot

\section{Conclusions}

A PMBLDC motor has been proposed and analyzed for the application of three wheeler rickshaw. Complete design of motor is carried along with analytical calculations and finite element analysis is used to analyze the performance of the motor. The results obtained show a good design with reduced losses, higher efficiency, and current density within limits. Further work can be done in optimization of the same motor and be realized in hardware to test actual performance also.

\section{References}

[1] Frede Blaabjerg, Dan M. Ionel, Renewable Energy Devices and Systems with Simulations in MATLAB ${ }$ and ANSYS $®$, CRC Press, 2017.

[2] Meherdad Eshani, Yimin gao and Ali Emadi, Modern-Electric, Hybrid-Electric and-Fuel-CellVehicles: Fundamentals, theory and design, CRC Press, 2009

[3] A. Emadi, Y.-J. Lee, and K. Rajashekara, "Power electronics and motor drives in electric, hybrid electric, and plug-in hybrid electric vehicles," IEEE Transactions on Industrial Electronics, vol. 55, no. 6, pp. 2237-2245, June 2008.

[4] X. Nian, F. Peng and H. Zhang, "Regenerative Braking System of Electric Vehicle Driven by Brushless DC Motor," in IEEE Transactions on Industrial Electronics, vol. 61, no. 10, pp. 57985808, Oct. 2014 
[5] M. Krishnamurthy, C. S. Edrington, A. Emadi, P. Asadi, M. Ehsani, and B. Fahimi, "Making the case for applications of switched reluctance motor technology in automotive products," IEEE Transactions on Power Electronics, vol. 21, no. 3, pp. 659-675, May 2006.

[6] J. Cao and B. Cao,'Fuzzy-logic - Based Sliding Mode Controller Design for Position -Sensorless Electric vehicle," IEEE Trans.Power Electron. vol. 24, no. 10, pp. 2368--- 2378, October 2009

[7] J. Cao, B. Cao, Z. Bai , P. Xu and X. Wu ," Neural network control of Electric Vehicle based on Position -Sensor less Brushless DC Motor," Proceedings of the IEEE Int. Conf. on Automation And logistics, pp. 2029-2034, August 2007.

[8] Z.Q. Zhu, David Howe, "Electric machines and drives for electric hybrid and fuel cell vehicles", Proceedings of IEEE, vol. 95, no. 4, pp. 746-765, Apr 2007.

[9] R. Kumar and B. Singh, "Buck-boost converter fed BLDC motor drive for solar PV array based water pumping," 2014 IEEE International Conference on Power Electronics, Drives and Energy Systems (PEDES), Mumbai, 2014, pp. 1-6.

[10] B. Singh V. Bist "A BL-CSC Converter Fed BLDC Motor Drive with Power Factor Correction" IEEE Transactions on Industrial Electronics no. 992014.

[11] R. Kumar and B. Singh, "Buck-boost converter fed BLDC motor drive for solar PV array based water pumping," 2014 IEEE International Conference on Power Electronics, Drives and Energy Systems (PEDES), Mumbai, 2014, pp. 1-6.

[12] B. Singh V. Bist "A BL-CSC Converter Fed BLDC Motor Drive with Power Factor Correction" IEEE Transactions on Industrial Electronics no. 992014.

[13] J.F. Gieras and Wing, Permenent Magnet Motor Technology, Marcel Dekker Inc, New York, 1997

[14] R. Qu, M. Aydin, T.A. Lipo, "Performance comparison of dualrotor radial-flux and axial-flux permanent-magnet BLDC machines", in proc. IEEE Int. Elect. Mach. Drives Conf, pp. 1948-1954, 2003.

[15] K. Sitapati, R. Krishnan, "Performance comparisons of radial and axial field permanent magnet brushless machines", IEEE Trans. Ind. Appl, vol. 37, no. 5, pp. 1219-1226, 2001.

[16] N.B. Simisie, H.B. Ertan, "A comparison of torque capabilities of axial flux and radial flux type of brushless dc (BLDC) drives for wide speed range applications", in proc. IEEE PEDS Honk Kong, pp. 719-724, 1999.

[17] R Qu, T A Lipo, "Dual-rotor radial-flux torodially wound permanent-magnet machines", IEEE Trans. Industry Applications, vol. 39, no. 6, pp. 1665-1673, 2003.

[18] R. Qu, T.A. Lipo, "Design and parameter effect analysis of dual-rotor radial flux toroidally wound permanent magnet machines", IEEE Trans. Industry Applications, vol. 40, no. 3, pp. 771-779, 2004.

[19] Duane C. Hanselman, Brushless Permanent-Magnet Motor Design, New York: McGraw-Hill Inc., 1994.

[20] T. J. E. Miller, Brushless Permanent-Magnet and Reluctance Motor Drives, Clarendon Press, Oxford, 1989.

[21] J. R. Hendershot Jr. and T. J. E Miller, Design of Permanent Magnet Motors, Oxford, U.K: Oxford Univ. Press, 1994 